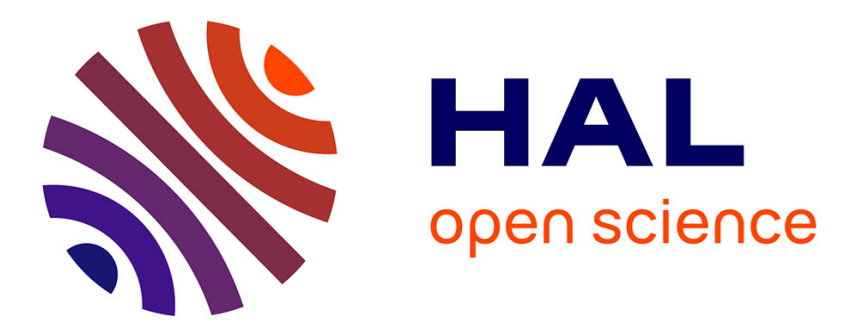

\title{
Evidence of O-Polar (000-1) ZnO Surfaces Induced by In Situ Ga Doping
}

\author{
Vincent Sallet, Corinne Sartel, Christophe Arnold, Said Hassani, Christèle \\ Vilar, Gaelle Amiri, Alain Lusson, Pierre Galtier, Julien Barjon, Karine \\ Masenelli-Varlot, et al.
}

\section{To cite this version:}

Vincent Sallet, Corinne Sartel, Christophe Arnold, Said Hassani, Christèle Vilar, et al.. Evidence of O-Polar (000-1) ZnO Surfaces Induced by In Situ Ga Doping. physica status solidi (RRL) - Rapid Research Letters, 2020, pp.2000037. 10.1002/pssr.202000037 . hal-02615169

\section{HAL Id: hal-02615169 \\ https://hal.science/hal-02615169}

Submitted on 20 Nov 2020

HAL is a multi-disciplinary open access archive for the deposit and dissemination of scientific research documents, whether they are published or not. The documents may come from teaching and research institutions in France or abroad, or from public or private research centers.
L'archive ouverte pluridisciplinaire HAL, est destinée au dépôt et à la diffusion de documents scientifiques de niveau recherche, publiés ou non, émanant des établissements d'enseignement et de recherche français ou étrangers, des laboratoires publics ou privés. 


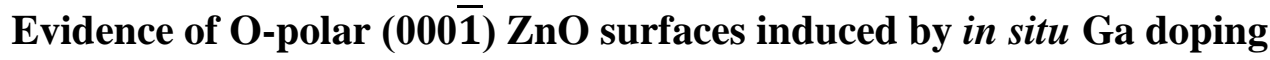

Vincent Sallet*, Corinne Sartel, Christophe Arnold, Said Hassani, Christèle Vilar, Gaelle Amiri, Alain Lusson, Pierre Galtier, Julien Barjon, Karine Masenelli-Varlot, Bruno Masenelli

Dr. V. Sallet, Dr. C. Sartel, Dr. C. Arnold, Dr. S. Hassani, C. Vilar, Dr. G. Amiri, Dr. A. Lusson, Prof. P. Galtier, Dr. J. Barjon

Université Paris-Saclay, CNRS, Université de Versailles St Quentin en Yvelines, Groupe d'Etude de la Matière Condensée (GEMAC), 45 avenue des Etats-Unis, 78035 Versailles,

France

Dr. K. Masenelli-Varlot

Université de Lyon, INSA-Lyon, UCBL, MATEIS, UMR CNRS 5510, F-69621 Villeurbanne, France

Prof. B. Masenelli

Institut des Nanotechnologies de Lyon (INL-UMR5270), Université de Lyon, INSA-Lyon, ECL, UCBL, CPE, CNRS, 69621 Villeurbanne, France

\section{KEYWORDS}

$\mathrm{ZnO}$ nanowires, transmission electron microscopy, doping, crystal facets, polarity. 


\section{ABSTRACT}

Controlling the facet orientation and polarity of semiconductor nanostructures is a major issue for achieving devices requiring specific surface properties. In this work, new facets are created during the growth of $\mathrm{ZnO}$ nanowires by metal-organic chemical vapor deposition, as a consequence of the trimethylgallium flow introduced in the gas phase. This in situ Ga-doping induces original shapes such as "Christmas tree"-like and "Taipei tower"-like nanostructures, developed along the $\mathrm{C}$-axis direction. In particular, lateral facets exhibit polar surfaces normal to this growth direction, which can be seen either as overhangs (for Christmas trees) or as terraces (for Taipei towers). In both cases, convergent beam electron diffraction reveals that those surfaces are O-polar $(000 \overline{1})$ planes, so that the two kinds of nano-objects grow with opposite polarities, i.e. Zn-polar $(+\mathrm{C})$ for Christmas trees and O-polar $(-\mathrm{C})$ for Taipei towers. By confirming previously published theoretical calculations, this work is an experimental evidence that $\mathrm{Ga}$ doping favors the growth of O-polar $\mathrm{ZnO}$ facets instead of the non-polar $\mathrm{M}$ surfaces usually developed for undoped $\mathrm{ZnO}$ nanowires. Nano-cathodoluminescence studies emphasize the intense near band edge emission of the nanostructures in the UV range, demonstrating their high optical quality. 


\section{MAIN TEXT}

For air and water quality monitoring, as for medical diagnosis, metal oxide semiconductor nanostructures have demonstrated their ability to detect small concentration of gases or impurities with high sensitivities. In addition, indoor air purification and water depollution can be achieved by using the photo-catalysis properties of metal oxides surfaces. ${ }^{[1,2,3]}$ One of the most studied materials is zinc oxide $(\mathrm{ZnO})$, a wide bandgap semiconductor combining a unique set of physical properties: direct bandgap, large exciton binding energy, piezoelectricity, biocompatibility, and made of earth-abundant elements. Among the noticeable features of $\mathrm{ZnO}$, surface reactivity has been particularly emphasized and investigated, as it plays a major role in gas sensing demonstrators and photo-catalysis applications. Recent progresses in $\mathrm{ZnO}$ nanomaterials, which benefit from a large variety of sizes, shapes, compositions, and functionalized surfaces, emphasized the huge potential for chemical sensors. ${ }^{[4]}$. Due to its noncentrosymmetric wurtzite structure, $\mathrm{ZnO}$ reveals a dipole moment in the unit cell volume, leading to a spontaneous polarization parallel to the C-axis. In the crystal, M (10 $\overline{1} 0)$ and A $(11 \overline{2} 0)$ planes are non-polar, unlike $+\mathrm{C}(0001)$ and $-\mathrm{C}(000 \overline{1})$ planes that are polar surfaces and can be referred as Zn-polar and O-polar surfaces, respectively. Each type of surface showing specific properties and reactivities, ${ }^{[5,6,7]}$ controlling facets orientation as well as polarity during $\mathrm{ZnO}$ crystal growth is a primordial issue for future applications ${ }^{[8]}$. As an example, $\mathrm{ZnO}$ pyramids with semi-polar $\{10 \overline{1} 1\}$ planes were shown to remarkably enhance the gas sensing response to ethanol. ${ }^{[9]}$

Today, $\mathrm{ZnO}$ nanostructures are commonly fabricated using a wide variety of growth techniques, ${ }^{[10]}$ including vapor growth (physical vapor transport, ${ }^{[11]}$ chemical vapor deposition ${ }^{[12]}$ ) and solution growth (hydrothermal, ${ }^{[13]}$ electrochemical deposition ${ }^{[14]}$ ). In particular, $\mathrm{ZnO}$ nanowires (NWs) easily grow along C-axis with Zn- or O- polarity depending on the employed technique and/or the substrate nature. ${ }^{[15]}$ In general, NWs develop six $M-\{10 \overline{1} 0\}$ lateral 
facets. ${ }^{[16]}$ Their spontaneous formation can be explained, to a certain extent, by the difference of surface energies: values of $2.25 \mathrm{~J} / \mathrm{m}^{2}$ for $\mathrm{C}(0001)$ and $1.12 \mathrm{~J} / \mathrm{m}^{2}$ for $\mathrm{M}\{10 \overline{1} 0\}$ have been calculated by $\mathrm{Na}$ et al. ${ }^{[17]}$ However, it is known that crystal facets can be engineered by in situ doping or by adding a surfactant in the gas/liquid phase. ${ }^{[18]}$ Recently, we have reported the transformation of ZnO NWs morphologies induced by trimethylgallium (TMGa) doping during metalorganic chemical vapor deposition (MOCVD). ${ }^{[19]}$ The effects have been understood as a surfactant behavior of $\mathrm{Ga}$ atoms on the growing facets that modifies surface energies and kinetics, and favors the appearance of new C-oriented polar facets. The identification of the facets polarity, $\mathrm{Zn}$ - or O-polar, was nevertheless still to be done, and remained as an open question. The present letter continues our former article and aims to give a clear answer. In this work, Ga-doped ZnO (GZO) NWs are grown using the so-called VLS (vapor solid liquid) or VSS (vapor solid solid) process, i.e. with the assistance of gold droplets acting as catalysts. ${ }^{[20]}$ The evolution of the morphology is followed as a function of the TMGa doping flow. Similarly to the case of spontaneously grown GZO NWs and core-shell $\mathrm{ZnO} / \mathrm{ZnO}$ :Ga NWs, ${ }^{[19]}$ new polar C-oriented facets appear upon doping, and a careful investigation of their polarities demonstrates that O-polar $(000 \overline{1})$ surfaces are favored, in agreement with previous theoretical work ${ }^{[21]}$ and electron counting rule. ${ }^{[22]}$ The optical quality of the grown GZO nanowires is finally assessed by cathodoluminescence (CL).

Figure 1 gathers SEM images of three samples grown on sapphire: non-intentionally doped Au-catalyzed ZnO NWs (Cat1) in figure 1a, while Ga-doped samples prepared with 0.09, and $0.22 \mu \mathrm{mol} / \mathrm{min}$ TMGa flow (Cat2-3) are presented in figures $1 \mathrm{~b}$ and $1 \mathrm{c}$, respectively. The undoped sample exhibits short nanorods, $\sim 1 \mu \mathrm{m}$ long and 100-200 nm in diameter. As presented in our previous article, ${ }^{[23]}$ such Au-catalyzed NWs grow with O-polar (0001) direction, unlike spontaneous $\mathrm{ZnO}$ nanowires (without catalyst) which show Zn-polarity. Introducing 0.09 $\mu \mathrm{mol} / \mathrm{min}$ of TMGa in the gas phase during the MOCVD growth leads to a drastic 
transformation of the $\mathrm{ZnO}$ nanostructures. Upon Ga doping, two kinds of conical structures are mainly observed, with lengths around 1-2 $\mu \mathrm{m}$ (figure $1 \mathrm{~b}$ ). One type of structure exhibits flat lateral surfaces with a decrease of the diameter from the base to the top of the nanocone where the Au droplet stands (red circle). In a different way, the second kind of structure shows multiple steps on the lateral facets, perpendicular to the growth direction (blue circle). At the bottom of the cones, a rough $3 \mathrm{D} \mathrm{ZnO}$ interfacial layer is present. Increasing the $\mathrm{TMGa}$ flow to 0.022 $\mu \mathrm{mol} / \mathrm{min}$ makes both morphologies evolve (figure 1c1). Steps and facets appear on the formerly flat sides (red circle). On the other morphology, the initial steps develop to give rise to more pronounced terraces around the cones, like a "Taipei tower" (blue circle). Unlike undoped ZnO NWs, Ga-doped nanostructures exhibit $\{10 \overline{1} 2\}$ and/or $\{10 \overline{1} 1\}$ inclined facets, with six-fold symmetry, and which are inclined at an angle of $15^{\circ}$ and $28^{\circ}$ relative to the $(10 \overline{10})$ M plane. Such transformation of the lateral facets has previously been explained by the rotation of the growth front around A-[11 $\overline{2} 0]$ direction, due to in situ Ga doping effects. ${ }^{[19]}$ We note that the average length of GZO nanostructures increases significantly at higher Ga content in the gas phase. More elongated structures with developed lateral facets were also fabricated (figure 1c2), in particular long "Christmas trees" with lengths up to $6 \mu \mathrm{m}$ (green circle). In addition, asymmetric nanowires are observed with one rough lateral side exhibiting steps and terraces, and another side much more flat, giving a "saw-blade" shape (see yellow circle).

Thus, in situ Ga doping has a strong influence on the growth mechanism and, as a consequence, on the final morphology. The axial growth rate, driven by the Au-catalyzed process, is enhanced by the presence of Ga. In ZnO VLS growth, Zn atoms are assumed to diffuse within a thin liquid skin on the surface of the Au-droplet, so that the core of this latter would remain solid. ${ }^{[24]}$ Following this mechanism, one can suggest that incorporating Ga in the $\mathrm{Au}$ catalyst will increase the thickness of the liquid skin or even turn the whole droplet to a liquid state. This would enhance the mean $\mathrm{Zn}$ concentration in the catalyst and the $\mathrm{Zn}$ diffusion 
towards the growing interface between the Au-Ga-Zn alloy and the nanowire, thus increasing the axial growth rate. No significant concentration of $\mathrm{Ga}$ has nevertheless been found in the Au-droplet, or it is below the detection limit of Energy-dispersive X-ray spectroscopy (EDX) at 0.5 at.\%. Thus we do not believe the whole droplet would act as a Ga reservoir like it is the case in GaAs NWs growth. ${ }^{[25]}$ The fraction of Ga incorporated in the catalyst may also exhaust from the droplet during the cooling down from $1000^{\circ} \mathrm{C}$ to room temperature, after switching off the precursors flow at the end of the growth.

Au-catalyzed GZO NWs exhibit new facets corresponding to C-polar surfaces, perpendicular to the growth direction. Then, the question that is naturally emerging is related to their polarity: is it $\mathrm{Zn}$ - or O-polar? Transmission electron microscopy (TEM) and convergent beam electron diffraction (CBED) have been used to tackle this issue. To this end, we have chosen to focus on two populations of GZO nanostructures, called Christmas trees and Taipei towers, which were highlighted in figure 1 (green and blue circles, respectively). TEM images are presented in figure 2. It is important to note that the two nanostructures presented in this figure come from the same sample (Cat3), and were selected after scratching the surface and spreading the nanowires on the carbon membrane of a TEM copper grid. Both types of NWs are elongated structures but they are distinct by the shape of their lateral facets. A Taipei tower exhibits terraces that can be seen by looking at the object from above (i.e. from the gold catalyst), whereas a Christmas tree shows overhangs that can be seen from below (i.e. from the substrate). The corresponding experimental and simulated CBED patterns are also presented in figure 2 . The patterns are not symmetric and the comparison unambiguously allows the determination of the NW growth direction. Interestingly, Taipei towers grow along the $-\mathrm{C}$ direction (O-polarity), while Christmas trees show the opposite, i.e. a $+\mathrm{C}$ growth direction (Zn-polarity). As a consequence, the terraces seen on Taipei towers and the overhangs observed on the Christmas trees are all O-polar $(000 \overline{1})$ planes. These results clearly show that the emergence of a 
preferential O-polar surface is induced by Ga doping during MOCVD growth, whatever the polarity of the growing nanowire. To summarize, the growth mechanism can be described as a combination of two processes: i) the axial growth below the droplet due the catalyst, and ii) the lateral growth induced by impinging and diffusing atoms on the nanowire facets. If the growth direction is O-polar, then $(000 \overline{1})$ surfaces are generated and appear from above like terraces to

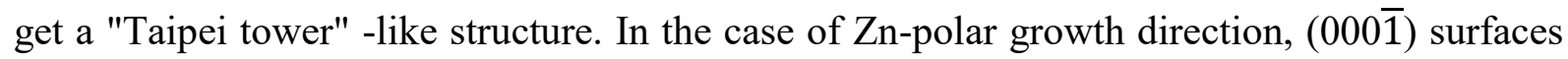
are also created but will be seen from below like overhangs, to obtain a Christmas tree. It is important to note that, unlike undoped $\mathrm{Au}$-catalyzed $\mathrm{ZnO} \mathrm{NWs}$ which all grow with O-polarity, Ga-doped NWs can grow either O- or Zn-polar. Such variety of GZO nanostructures observed in sample Cat3 (with $0.22 \mu \mathrm{mol} / \mathrm{min} \mathrm{TMGa}$ ) is most probably be due to the onset of the growth, when crawling-like nanowires initiate below the gold catalyst $\left[{ }^{26}\right]$, with various crystallographic relationships between substrate/ $\mathrm{ZnO}$, and/or $\mathrm{ZnO} /$ droplet. Emerging Christmas trees would show $(0001) \mathrm{ZnO} / \mathrm{Au}$ interface, while Taipei towers would show $(000 \overline{1}) \mathrm{ZnO} / \mathrm{Au}$ interface. In addition, "saw blade" structures observed in figure 1c2 may grow along A-axis and develop from $(11 \overline{2} 0) \mathrm{ZnO} / \mathrm{Au}$ interfaces, similarly to $\mathrm{ZnO}$ nanoribbons which were previously reported $\left[{ }^{27}\right]$.

$\mathrm{ZnO}$ nanostructures commonly exhibit different crystal facets, which result from specific kinetic parameters and surface activities during the growth, therefore determining the final morphology. This is particularly relevant in the MOCVD process, where a number of key parameters can be varied separately, such as substrate temperature, II/VI ratio or reactor pressure $\left[{ }^{27}\right]$. However, the emergence of polar C-surfaces is striking, and not usually observed. For undoped $\mathrm{ZnO} \mathrm{NWs}$, the favored surfaces are M-planes lateral facets at the expense of Cplanes. For high aspect ratio NWs, the topmost surface has a much reduced area and can be a (0001) plane, thus giving a flat tip to the nanowire, but it often shows $(10 \overline{1} \ell)$ inclined planes. ${ }^{[28]}$ As mentioned in the introduction, $\mathrm{ZnO}$ has a non-centrosymmetric structure with an internal 
electric field along the $\mathrm{C}$-axis. Cutting the crystal perpendicular to the $\mathrm{C}$-axis gives rise to two non-equivalent polar surfaces, namely $(0001)$ and $(000 \overline{1})$. Such surfaces are referred as Taskertype-3 (charged planes and dipole moment normal to the surface) and require to be stabilized to exist. In their article, ${ }^{[21]}$ Sohn et al. calculated the surface energy variations of $+\mathrm{C}(0001)$, $\mathrm{C}(000 \overline{1}), \mathrm{M}(10 \overline{1} 0)$ and $\mathrm{A}(11 \overline{2} 0)$ surfaces after replacing a half monolayer of $\mathrm{Zn}$ by Ga atoms. The surface energy increased for $\mathrm{M}$ and A planes $\left(+0.8\right.$ and $+0.9 \mathrm{~J} / \mathrm{m}^{2}$, respectively), was nearly unchanged for the Zn-polar $+\mathrm{C}$ plane $\left(+0.07 \mathrm{~J} / \mathrm{m}^{2}\right)$, while it strongly decreased for the O-polar $-\mathrm{C}$ plane, with an energy shift of $-1.85 \mathrm{~J} / \mathrm{m}^{2}$. Such reduction is understood in the framework of the Electron Counting Rule (ECR) that accounts for surface reconstructions and island structures ${ }^{[22]}$, and where electrons transfer from the dangling bonds of the electropositive element (e.g. Ga, Zn, with energy level in the conduction band) to the dangling bonds of the electronegative element (e.g. As, O, with energy level in the valence band). ECR requires a modified surface structure and the exact number of available electrons filling/emptying the dangling bond states. In our case, assuming the substitution of $\mathrm{Zn}$ with half-coverage of the Opolar surface, one Ga atom would bring one electron at high-energy $4 \mathrm{p}$ state that will fill two low-energy $\mathrm{O}$ dangling bonds states, these latter having only 1.5 electron occupancy. Therefore, the O-polar $\mathrm{ZnO}$ surface partially covered with Ga becomes very favorable for the growth. A major result of our study is that our observations, in particular the emergence of O-polar terraces and overhangs specifically developed in nanostructures of opposite polarities, agree with Sohn's calculation and ECR, giving experimental evidence of the theoretical prediction.

In supporting information, nano-cathodoluminescence studies on a single Christmas tree as well as on a single Taipei tower are detailed. Both nanostructures show intense near band edge emission in the UV range. In the case of the Christmas trees, a single emission at $373 \mathrm{~nm}$ is observed, with FWHM of $10 \mathrm{~nm}$, and it blue-shifts to $368 \mathrm{~nm}$ when moving the e-beam excitation near the tip. The Taipei tower structures generally show two CL peaks with less 
intense luminescence, compared to Christmas trees. A first emission at $369 \mathrm{~nm}$ has a constant wavelength and intensity along the nanostructure and could be attributed to Ga donor bound excitons, $\mathrm{D}^{\circ} \mathrm{X}(\mathrm{Ga})$. The second emission at lower energy is more intense than the first one, and varies in energy from 370 to $383 \mathrm{~nm}$ when moving the e-beam from the tip to the base.

In conclusion, adding trimethylgallium flow during the MOCVD growth of Au-catalyzed $\mathrm{ZnO}$ nanowires induces a transformation of the lateral facets, which leads to original $\mathrm{ZnO}$ nanoobjects such as Christmas trees and Taipei towers. Indeed, upon in situ Ga doping, $\mathrm{ZnO}$ nanowires specifically develop surfaces that have been clearly identified by CBED analysis as O-polar. Such influence is understood as the modification of surface energies due to a Ga partial coverage of the growing surfaces. From the general point of view of crystal growth, our observations, by evidencing how a specific surface appears, constitute an experimental confirmation of the potential of in situ doping regarding crystal facet engineering, and beyond that, a confirmation of the relevance of the ECR model.

Near band edge emission in the range [368-383 $\mathrm{nm}$ ] was observed by nanocathodoluminescence, and makes the nanomaterial suitable for optical and photonics devices. Moreover, the achievement of such $\mathrm{ZnO}$ nanostructures with developed O-polar surfaces may have potential interest for the realization of sensor devices or photo-catalysis applications that would require specific surface reactivity.

\section{Experimental section}

Ga-doped $\mathrm{ZnO}$ one dimensional nanostructures were fabricated on A plane (11 $\overline{2} 0)$ sapphire substrates by MOCVD in a horizontal RF-heated quartz reactor. Diethylzinc (DEZn), TMGa and nitrous oxide $\left(\mathrm{N}_{2} \mathrm{O}\right)$ were used as sources, with helium as carrier gas. The nanowires were 
grown at $1000^{\circ} \mathrm{C}$ by following the Au-catalyzed process, where Au droplets were previously formed on the substrate surface. Ga-doped samples were grown varying the TMGa flow from 0 (non-intentionally doped) to $0.22 \mu \mathrm{mol} / \mathrm{min}$. Details of the growth parameters are given in table 1 .

The nanostructure morphologies were studied by scanning electron microscopy (SEM, JEOL 7001F). The samples were placed in the microscope chamber without any specific preparation. Secondary electron images were either cross-sectional views or $45^{\circ}$-tilted views, and were acquired with an accelerating voltage of $10 \mathrm{kV}$.

Transmission electron microscopy (TEM) was carried out on a JEOL 2010F microscope operating at $200 \mathrm{kV}$. The samples were scratched and NWs were dry-deposited on a TEM Cu grid covered with a holey carbon film. High Resolution images and convergent electron beam diffraction (CBED) patterns were acquired on a Gatan Orius100 camera. In CBED, the electron beam was focused on a NW in an area close to $2 \mathrm{~nm}$ in diameter, and the convergence angle (angular opening $2 \alpha$ ) was about $10 \mathrm{mrad}$. The NW was oriented so as to be in three-beam conditions, with only waves $(0002)$ and $(000 \overline{2})$ giving rise to diffraction. LACBED (large-angle convergent beam electron diffraction) was also used to check the orientation of the CBED pattern with respect to the NW. In this mode, the high defocus induces the appearance of the image in the CBED pattern. Simulations of the CBED patterns were carried out using the

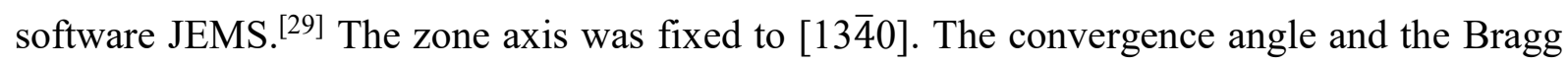
deviation were first chosen in accordance with experimental values. Then, patterns were simulated using Bloch waves and the sample thicknesses were adjusted to reproduce the Bragg line thicknesses.

The optical properties of individual nanowires have been investigated by using a cathodoluminescence setup mounted on the SEM (JEOL 7001F). In CL experiments, 
luminescence was collected by a parabolic mirror inserted in the SEM chamber. Light was then analyzed thanks to a Horiba Jobin Yvon spectrometer and spectra were recorded by a silicon liquid-nitrogen-cooled charge-coupled device. A GATAN cryostat SEM-stage maintained samples cooled at $10 \mathrm{~K}$ during measurements.

\section{Supporting information}

Supporting Information is available from the Wiley Online Library.

\section{Acknowledgements}

This work was supported by the French "Agence Nationale de la Recherche”, project n ${ }^{\circ}$ ANR15-CE09-0004 (GAZON). 


\section{REFERENCES}

[1] H. Ji, W. Zeng, Y. Li, Nanoscale 2019, 11(47), 22664.

[2] K.M. Lee, C.W. Lai, K.S. Ngai, J.C. Juan, Water Research 2016, 88, 428.

[3] E.M. Samsudin, S.B.A. Hamid, Applied Surface Science 2017, 391, 326.

[4] S. Chaudhary, A. Umar, K.K. Bhasin, S. Baskoutas, Materials 2018, 11.

[5] C. Wöll, Progress in Surface Science 2007 82, 55

[6] R. Heinhold, G.T. Williams, S.P. Cooil, D.A. Evans, M.W. Allen, Phys. Rev. B 2013, 88, 235315.

[7] Y. Adachi, N. Saito, I. Sakaguchi, T.T. Suzuki, Thin Solid Films 2019, 685, 238.

[8] J. Zúñiga-Pérez, V. Consonni, L. Lymperakis, X. Kong, A. Trampert, S. Fernández-Garrido, O. Brandt, H. Renevier, S. Keller, K. Hestroffer, M.R. Wagner, J.S. Reparaz, F. Akyol, S. Rajan, S. Rennesson, T. Palacios, G. Feuillet, Applied Physics Reviews 2016, 3, 041303.

[9] N. Saito, K. Watanabe, H. Haneda, I. Sakaguchi, K. Shimanoe, J. Phys. Chem. C 2018, 122, 7353

[10] J. Theerthagiri, S. Salla, R.A. Senthil, P. Nithyadharseni, A. Madankumar, P. Arunachalam, T. Maiyalagan, H.-S. Kim, Nanotechnology 2019, 30, 392001.

[11] A.C. Mofor, A.S. Bakin, A. Elshaer, D. Fuhrmann, F. Bertram, A. Hangleiter, J. Christen, A. Waag, Applied Physics A 2007, 88, 17.

[12] B. Ren, X. Zhang, M. Zhao, X. Wang, J. Ye, D. Wang, AIP Advances 2018, 8, 015206.

[13] D. Sakai, K. Nagashima, H. Yoshida, M. Kanai, Y. He, G. Zhang, X. Zhao, T. Takahashi, T. Yasui, T. Hosomi, Y. Uchida, S. Takeda, Y. Baba, T. Yanagida, Scientific Reports 2019, 9, 14160 .

[14] M.D. Reyes Tolosa, J. Orozco-Messana, A.N.C. Lima, R. Camaratta, M. Pascual, M.A. Hernandez-Fenollosa, Journal of The Electrochemical Society 2011, 158, E107.

[15] T. Cossuet, E. Appert, J.-L. Thomassin, V. Consonni, Langmuir 2017, 33,6269.

[16] F. Falyouni, L. Benmamas, C. Thiandoume, J. Barjon, A. Lusson, P. Galtier, V. Sallet, Journal of Vacuum Science \& Technology B: Microelectronics and Nanometer Structures Processing, Measurement, and Phenomena 2009, 27, 1662.

[17] S.H. Na, C.H. Park, Journal of the Korean Physical Society 2009, 54, 867.

[18] S.-M. Lam, M.-W. Kee, J.-C. Sin, Materials Chemistry and Physics 2018 212, 35. 
[19] V. Sallet, C. Sartel, S. Hassani, C. Vilar, G. Amiri, A. Lusson, F. Jomard, P. Galtier, I. Lefebvre, C. Delerue, M.K. Hamza, B. Canut, B. Masenelli, Crystal Growth \& Design 2018, $18,4287$.

[20] S. Barth, F. Hernandez-Ramirez, J.D. Holmes, A. Romano-Rodriguez, Progress in Materials Science 2010, 55, 563.

[21] J.I. Sohn, W.-K. Hong, S. Lee, S. Lee, J. Ku, Y.J. Park, J. Hong, S. Hwang, K.H. Park, J.H. Warner, S. Cha, J.M. Kim, Scientific Reports 2014, 4, 5680.

[22] M.D. Pashley, Phys. Rev. B 1989, 40, 10481.

[23] V. Sallet, C. Sartel, C. Vilar, A. Lusson, P. Galtier, Applied Physics Letters 2013, 102, 182103.

[24] H. Simon, T. Krekeler, G. Schaan, W. Mader, Crystal Growth \& Design 2013, 13, 572.

[25] J.C. Harmand, G. Patriarche, N. Péré-Laperne, M.-N. Mérat-Combes, L. Travers, F. Glas, Applied Physics Letters 2005, 87, 203101.

[26] I. Levin, A. Davydov, B. Nikoobakht, N. Sanford, and P. Mogilevsky, Applied Physics Letters 2005, 87, 103110.

[27] V. Sallet, in Wide Band Gap Semiconductor Nanowires 1: Low-Dimensionality Effects and Growth, (Eds: V. Consonni and G. Feuillet), Wiley-ISTE, Hoboken, USA 2014, pp.265302

[28] D.J. Park, J.Y. Lee, D.C. Kim, H.K. Cho, Journal of Physics D: Applied Physics 2008, 42, 035413.

[29] P.A. Stadelmann, Ultramicroscopy 1987, 21, 131. 


\section{FIGURES}
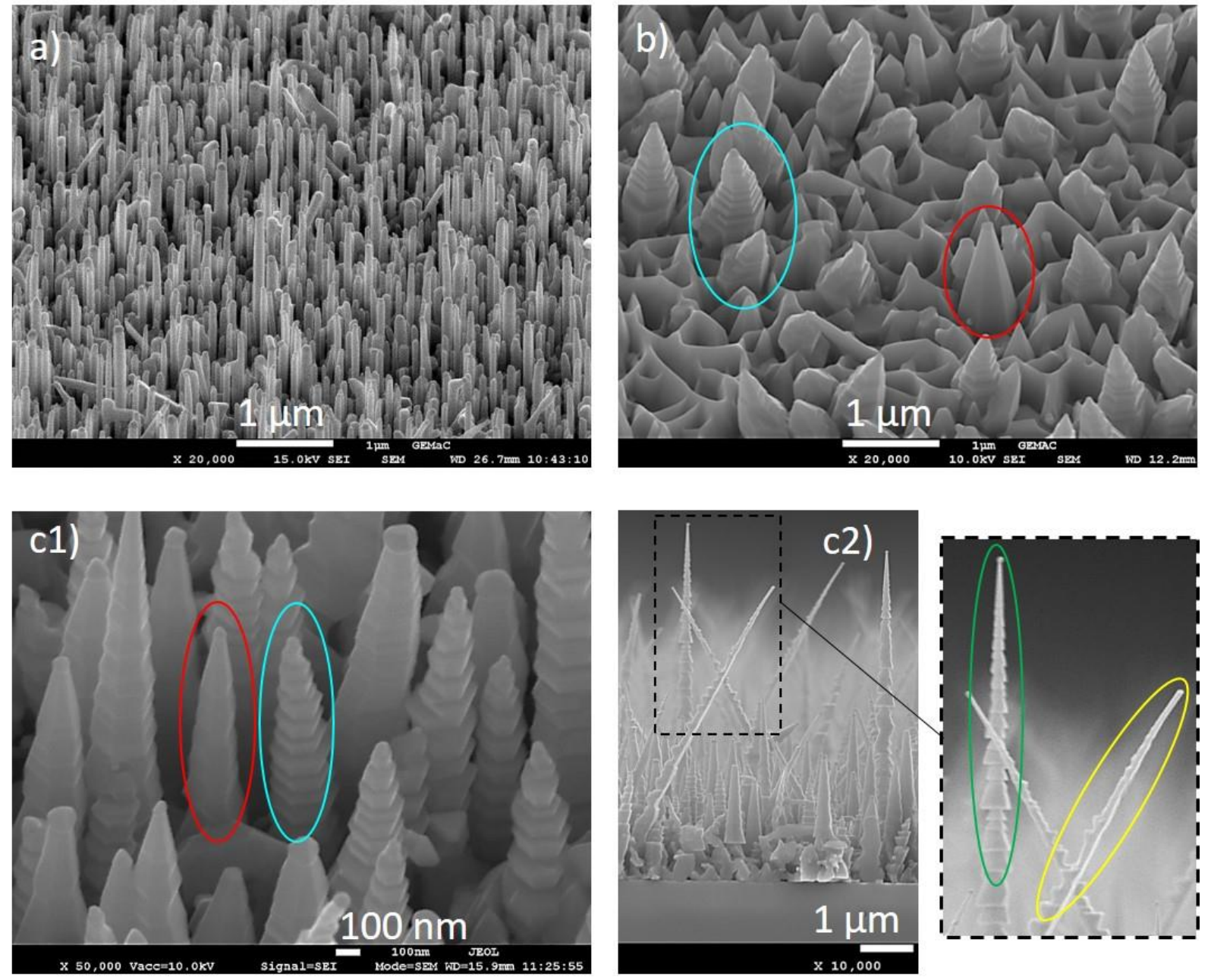

Figure 1. SEM images of samples grown on sapphire : a) undoped Au-catalyzed ZnO NWs (sample Cat1), b) Ga-doped Au-catalyzed ZnO NWs prepared with $0.09 \mu \mathrm{mol} / \mathrm{min}$ TMGa flow (Cat2), c1-c2 and zoomed insert) with $0.22 \mu \mathrm{mol} / \mathrm{min}$ TMGa (Cat3) 

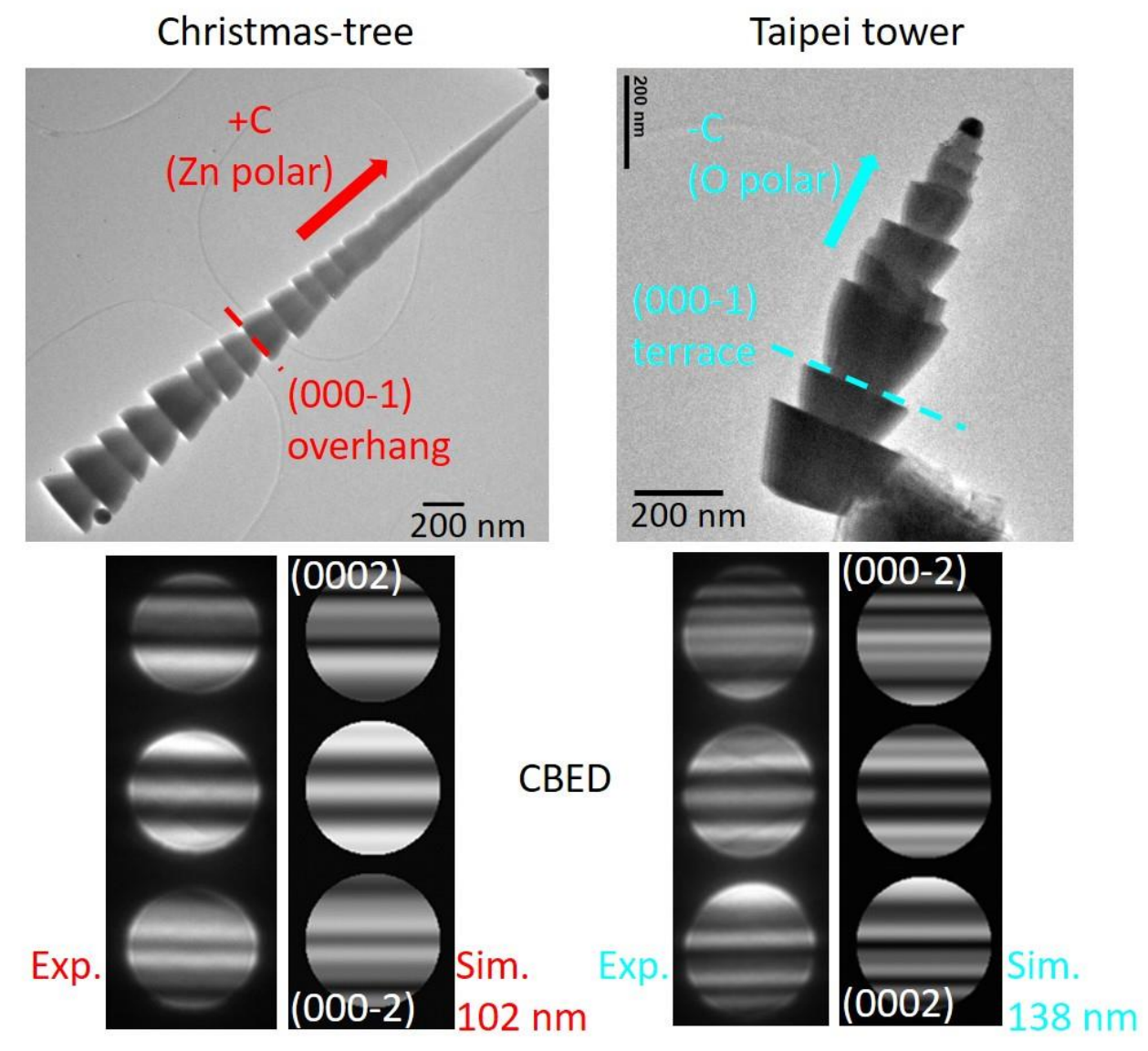

Figure 2. TEM analysis of a Ga-doped Au-catalyzed ZnO NWs sample grown on sapphire substrate with $0.22 \mu \mathrm{mol} / \mathrm{min}$ TMGa flow (sample Cat3). The nanostructures are scratched and spread on a holey carbon grid to isolate Taipei tower and Christmas tree structures. CBED analysis and JEMS simulations (with adjusted thicknesses) of the two nanostructures enable to identify the growth axis polarity. 


\section{TABLES}

\begin{tabular}{|c|c|c|c|c|c|c|}
\hline Sample & $\begin{array}{c}\text { Structure } \\
\text { type }\end{array}$ & Tg & $\begin{array}{c}\text { Growth } \\
\text { time }\end{array}$ & $\begin{array}{c}\text { DEZn flow } \\
(\boldsymbol{\mu m o l} / \mathbf{m i n})\end{array}$ & $\begin{array}{c}\mathbf{N}_{2} \text { O flow } \\
(\boldsymbol{\mu m o l} / \mathbf{m i n})\end{array}$ & $\begin{array}{c}\text { TMGa flow } \\
(\boldsymbol{\mu m o l} / \mathbf{m i n})\end{array}$ \\
\hline Cat1 & Catalyst- & $1000^{\circ} \mathrm{C}$ & $20 \mathrm{~min}$ & 40 & 32000 & 0 \\
Cat2 & assisted & & & 40 & 32000 & 0.09 \\
Cat3 & NWs & & & 40 & 32000 & 0.22 \\
\hline
\end{tabular}

Table 1. MOCVD conditions used for $\mathrm{ZnO}$ :Ga nanostructures growth 


\section{TABLE OF CONTENTS}

Keyword : crystal faceting

Vincent Sallet, Corinne Sartel, Said Hassani, Christèle Vilar, Gaelle Amiri, Alain Lusson, Pierre Galtier, Christophe Arnold, Julien Barjon, Karine Masenelli-Varlot, Bruno Masenelli

\section{Evidence of O-polar (0001) $\mathrm{ZnO}$ surfaces induced by in situ Ga doping.}

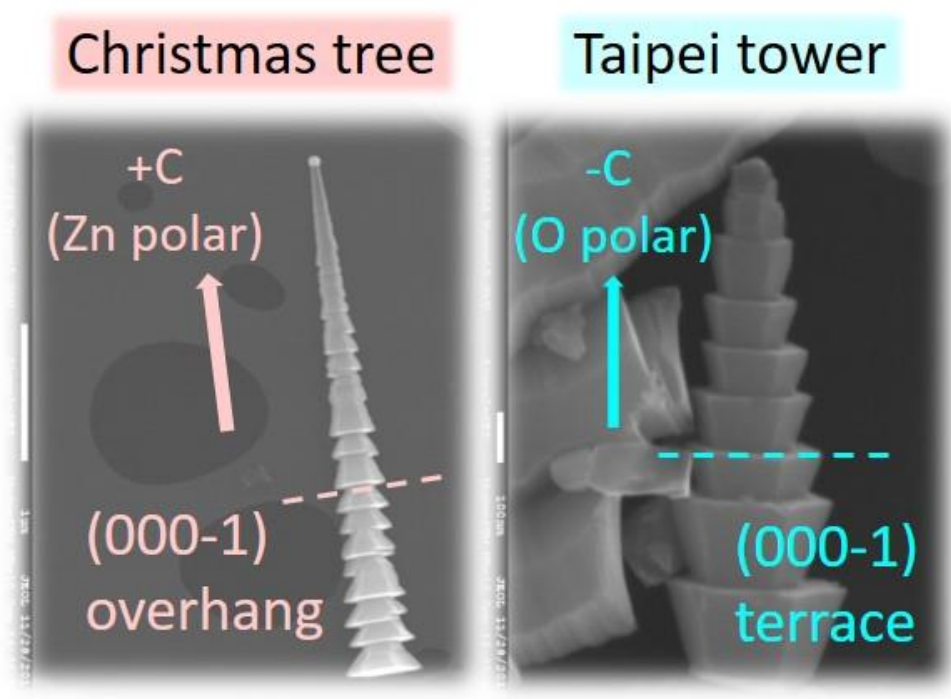

In situ $\mathrm{Ga}$ doping during the MOCVD growth of Au-catalyzed $\mathrm{ZnO}$ nanowires induces the formation of new O-polar surfaces, demonstrating that crystal facet engineering can be achieved through a modification of surface energies. Nanostructures having opposite polarities are generated : Christmas trees grown along $+\mathrm{C}(0001)$ axis exhibit overhangs, while Taipei towers grown along $-\mathrm{C}(000 \overline{1})$ axis show terraces. 


\section{Supporting information}

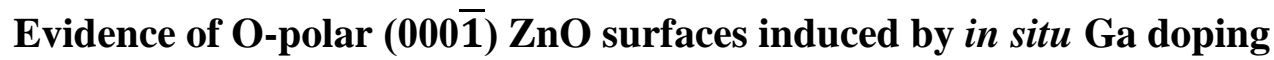

Vincent Sallet*, Corinne Sartel, Christophe Arnold, Said Hassani, Christèle Vilar, Gaelle

Amiri, Alain Lusson, Pierre Galtier, Julien Barjon, Karine Masenelli-Varlot, Bruno Masenelli

To further check the crystalline quality of the nanostructures, nano-cathodoluminescence studies have been carried out at 10K in a SEM. Figure S1 gathers the CL spectra recorded on a Christmas tree as well as on a Taipei tower. Both nanostructures show intense near band edge emission in the UV range, demonstrating the global high optical quality of the grown material. In the case of the Christmas trees, a single emission at $373 \mathrm{~nm}$ is observed, with FWHM of 10 $\mathrm{nm}$. In addition, it is noticed that the energy varies depending on the e-beam excitation location along the nanowires. From $368 \mathrm{~nm}$ close to the top, the energy gradually red-shifts to reach 373 $\mathrm{nm}$ when getting closer to the base of nanostructure. The Taipei tower structures generally show a less intense luminescence and, noticeably, quite different behavior as two CL peaks are detected. A first emission at $369 \mathrm{~nm}$ could be attributed to Ga donor bound excitons, $\mathrm{D}^{\circ} \mathrm{X}(\mathrm{Ga})$, and this peak has a constant wavelength and intensity along the nanostructure. The second

emission at lower energy is more intense than the first one, and varies in energy from 370 to $383 \mathrm{~nm}$ when moving the e-beam from the tip to the base, similarly to the case of the Christmas tree. The occurrence of such low energy emission could be due to defects or impurities in the largest parts of the nanostructures, nevertheless no extended defects such as twins or stacking faults have been observed by TEM at this stage. 

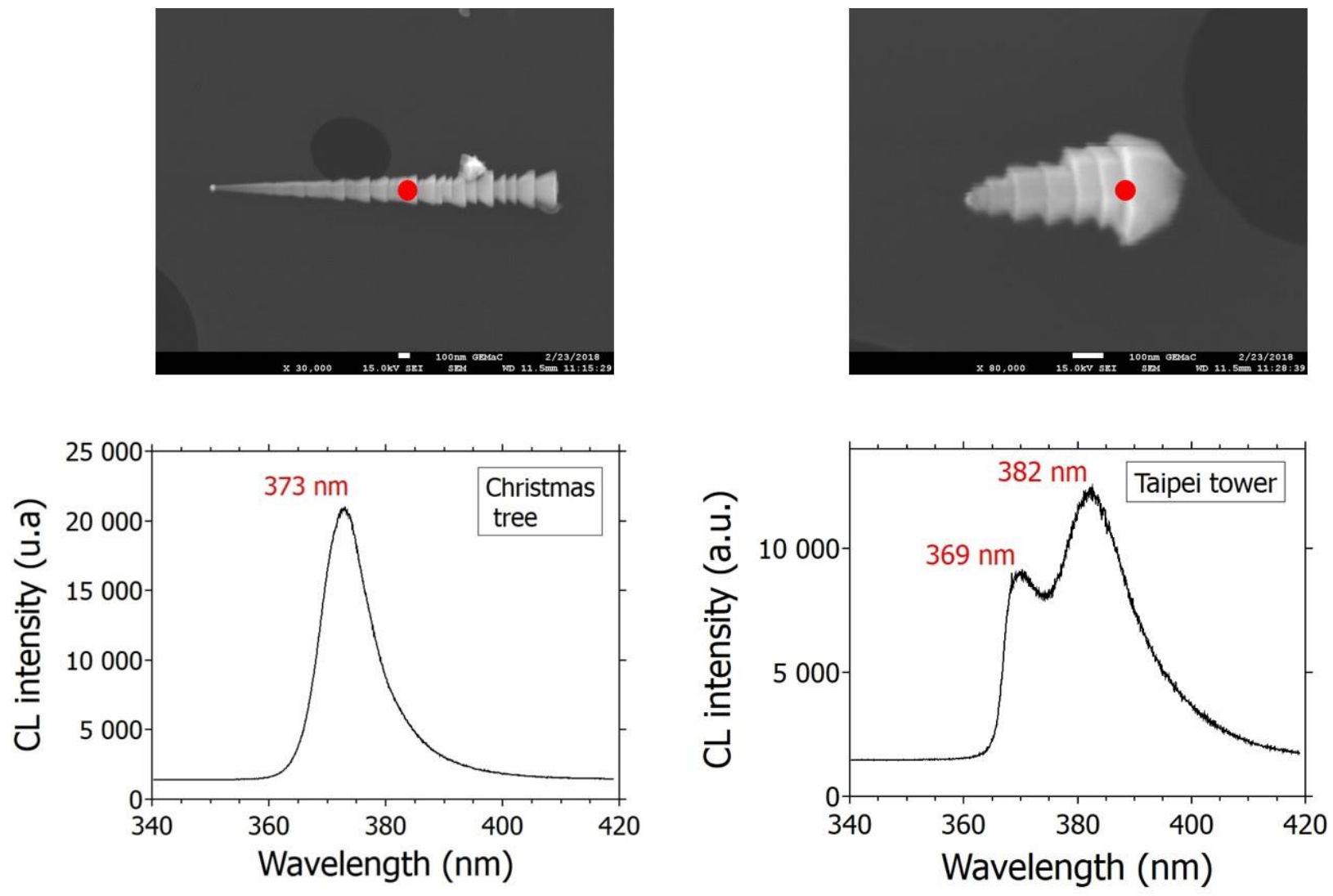

Figure S1. SEM images and corresponding nano-cathodoluminescence spectra of

Christmas tree and Taipei tower structures (sample Cat3); the red spots indicate the excited areas in CL. 


\section{REFERENCES}

${ }^{1}$ H. Ji, W. Zeng, Y. Li, Nanoscale 2019, 11(47), 22664.

${ }^{2}$ K.M. Lee, C.W. Lai, K.S. Ngai, J.C. Juan, Water Research 2016, 88, 428.

${ }^{3}$ E.M. Samsudin, S.B.A. Hamid, Applied Surface Science 2017, 391, 326.

${ }^{4}$ S. Chaudhary, A. Umar, K.K. Bhasin, S. Baskoutas, Materials 2018, 11.

${ }^{5}$ C. Wöll, Progress in Surface Science 2007 82, 55

${ }^{6}$ R. Heinhold, G.T. Williams, S.P. Cooil, D.A. Evans, M.W. Allen, Phys. Rev. B 2013, 88, 235315.

${ }^{7}$ Y. Adachi, N. Saito, I. Sakaguchi, T.T. Suzuki, Thin Solid Films 2019, 685, 238.

${ }^{8}$ J. Zúñiga-Pérez, V. Consonni, L. Lymperakis, X. Kong, A. Trampert, S. Fernández-Garrido, O. Brandt, H. Renevier, S. Keller, K. Hestroffer, M.R. Wagner, J.S. Reparaz, F. Akyol, S. Rajan, S. Rennesson, T. Palacios, G. Feuillet, Applied Physics Reviews 2016, 3, 041303.

${ }^{9}$ N. Saito, K. Watanabe, H. Haneda, I. Sakaguchi, K. Shimanoe, J. Phys. Chem. C 2018, 122, 7353

${ }^{10}$ J. Theerthagiri, S. Salla, R.A. Senthil, P. Nithyadharseni, A. Madankumar, P. Arunachalam, T. Maiyalagan, H.-S. Kim, Nanotechnology 2019, 30, 392001.

${ }^{11}$ A.C. Mofor, A.S. Bakin, A. Elshaer, D. Fuhrmann, F. Bertram, A. Hangleiter, J. Christen, A. Waag, Applied Physics A 2007, 88, 17.

${ }^{12}$ B. Ren, X. Zhang, M. Zhao, X. Wang, J. Ye, D. Wang, AIP Advances 2018, 8, 015206.

${ }^{13}$ D. Sakai, K. Nagashima, H. Yoshida, M. Kanai, Y. He, G. Zhang, X. Zhao, T. Takahashi, T. Yasui, T. Hosomi, Y. Uchida, S. Takeda, Y. Baba, T. Yanagida, Scientific Reports 2019, 9, 14160 .

${ }^{14}$ M.D. Reyes Tolosa, J. Orozco-Messana, A.N.C. Lima, R. Camaratta, M. Pascual, M.A. Hernandez-Fenollosa, Journal of The Electrochemical Society 2011, 158, E107.

15 T. Cossuet, E. Appert, J.-L. Thomassin, V. Consonni, Langmuir 2017, 33,6269.

${ }^{16}$ F. Falyouni, L. Benmamas, C. Thiandoume, J. Barjon, A. Lusson, P. Galtier, V. Sallet, Journal of Vacuum Science \& Technology B: Microelectronics and Nanometer Structures Processing, Measurement, and Phenomena 2009, 27, 1662.

${ }^{17}$ S.H. Na, C.H. Park, Journal of the Korean Physical Society 2009, 54, 867.

${ }^{18}$ S.-M. Lam, M.-W. Kee, J.-C. Sin, Materials Chemistry and Physics 2018 212, 35. 
${ }^{19}$ V. Sallet, C. Sartel, S. Hassani, C. Vilar, G. Amiri, A. Lusson, F. Jomard, P. Galtier, I. Lefebvre, C. Delerue, M.K. Hamza, B. Canut, B. Masenelli, Crystal Growth \& Design 2018, $18,4287$.

${ }^{20}$ S. Barth, F. Hernandez-Ramirez, J.D. Holmes, A. Romano-Rodriguez, Progress in Materials Science 2010, 55, 563.

${ }^{21}$ J.I. Sohn, W.-K. Hong, S. Lee, S. Lee, J. Ku, Y.J. Park, J. Hong, S. Hwang, K.H. Park, J.H. Warner, S. Cha, J.M. Kim, Scientific Reports 2014, 4, 5680.

${ }^{22}$ M.D. Pashley, Phys. Rev. B 1989, 40, 10481.

${ }^{23}$ V. Sallet, C. Sartel, C. Vilar, A. Lusson, P. Galtier, Applied Physics Letters 2013, 102 , 182103.

${ }^{24}$ H. Simon, T. Krekeler, G. Schaan, W. Mader, Crystal Growth \& Design 2013, 13, 572.

${ }^{25}$ J.C. Harmand, G. Patriarche, N. Péré-Laperne, M.-N. Mérat-Combes, L. Travers, F. Glas, Applied Physics Letters 2005, 87, 203101.

${ }^{26}$ I. Levin, A. Davydov, B. Nikoobakht, N. Sanford, and P. Mogilevsky, Applied Physics Letters 2005, 87, 103110.

${ }^{27}$ V. Sallet, in Wide Band Gap Semiconductor Nanowires 1: Low-Dimensionality Effects and Growth, (Eds: V. Consonni and G. Feuillet), Wiley-ISTE, Hoboken, USA 2014, pp.265-302

${ }^{28}$ D.J. Park, J.Y. Lee, D.C. Kim, H.K. Cho, Journal of Physics D: Applied Physics 2008, 42, 035413.

${ }^{29}$ P.A. Stadelmann, Ultramicroscopy 1987, 21, 131. 